Laura A. Janda

\title{
Metonymy and word-formation revisited
}

\begin{abstract}
Brdar and Brdar-Szabó (this volume) offer a critique of Janda (2011). Janda (2011) found that the same cognitive strategy that facilitates metonymy, namely use of a conceptual source to access a target, can also be invoked in many patterns of affixal word-formation. In other words, many cases of word-formation appear to be motivated by metonymic association. Brdar and Brdar-Szabó claim that it is incorrect to refer to word-formational processes as metonymies. In addition to the robust parallels evidenced in my data, I offer three arguments to defend my use of the term "metonymy": (1) a broader definition of metonymy facilitates more insightful generalizations; (2) there is no fixed boundary between lexical metonymy and word-formational metonymy since they coexist in the lexicon-grammar continuum; and (3) context, whether it be a suffix or other cues, is always a factor in metonymy.
\end{abstract}

Keywords: metonymy, word-formation

DOI 10.1515/cog-2014-0008

Received October 9, 2013; revised April 14, 2014; accepted April 16, 2014.

\section{Introduction}

Brdar and Brdar-Szabó (this volume) make a valuable contribution in that they focus on an issue that has attracted considerable attention in the scholarly literature, namely the relationship between metonymy and word-formation. We do indeed need more thorough studies of this relationship. I welcome further investigations and debate on this issue.

In this rebuttal, I choose to put aside the polemical queries into the quality of my scholarship raised by Brdar and Brdar-Szabó and focus instead on the key linguistic questions they raise. I will open with a concise restatement of the main points made in Janda (2011), and then turn to the issues regarding use of terminology, gradience in linguistic phenomena, the role of context and domain in defining metonymy, and the data used in Janda (2011).

Laura Janda: UiT The Arctic University of Norway. Email: laura.janda@uit.no 


\section{Main points of Janda (2011)}

In Janda (2011) I presented a systematic study of suffixal word-formation in Russian, Czech, and Norwegian. I showed that the cognitive strategy of using a conceptual source to access a target was manifest in the vast majority of suffixal derivations in those three languages, and indeed this is likely the case whenever there is productive affixation in any language. A close comparison of the sourcetarget patterns in my data with the patterns previously identified for lexical metonymy revealed robust parallels. This result is relevant to one of the core premises of cognitive linguistics, namely that phenomena of language can be accounted for by means of general cognitive strategies. In this case, I was able to show that the phenomena of suffixal word-formation can be largely motivated by the general cognitive strategy of metonymic association. It is certainly possible to disagree about whether the examples of suffixal word-formation I presented should be called "metonymies" (see Section 3). However, the parallels specified in Janda (2011) are valid regardless of where one stands on this terminological issue. The findings rest on a solid foundation of data. In order to refute the main point of Janda (2011), it would be necessary to show that the patterns described therein are in fact not present.

\section{Use of terminology}

Terminology is often a source of contention in academic disciplines. There is a dynamic tension between two laudable goals: one of maintaining rigor and control, and the other of discovering larger generalizations. Some scholars will prefer a more narrow definition of a given term, while others will prefer a broader one. In many instances the choice between a narrow vs. a broad interpretation cannot be arbitrated in absolute terms because neither choice is objectively better. Both choices come with their respective advantages and disadvantages. One can achieve tighter control at the expense of missing larger generalizations, or one can pursue generalizations facilitated by more open definitions.

Because scholars tend to disagree on the use of terms, it is customary for academic articles to open with definitions that set the terms for a given study. This is how my original article begins - with this definition of metonymy: "Metonymy is an inferential relationship between two concepts: a source concept is overtly named and provides mental access to a target concept in a given context" (Janda 2011: 360; see further discussion of this definition in Section 5).

In Janda (2011) I applied a broad definition of metonymy. Under this explicitly stated definition, I found evidence of consistent parallels between lexical 
metonymy and suffixal word-formation. These parallels are not merely postulated without evidence as claimed by Brdar and Brdar-Szabó (cf. "hardly any direct evidence” with reference to Janda 2011, "again provides practically no evidence" with reference to Janda 2008, "simply no empirical evidence” with reference to the distinction between lexical metonymy and word-formation in cognitive linguistics in general). I analyzed hundreds of examples collected in a conscious effort to represent the entire systems of suffixal derivation in the three languages, and the parallels emerged from careful analysis of the data.

Other scholars are certainly welcome to choose a more narrow definition of metonymy and proceed from such a definition. Those who prefer a more narrow definition will have to find some other way to account for the findings in Janda (2011), either by hedging, perhaps calling them "metonymy-like", or by calling them something else altogether. The latter solution entails ignoring the relation to metonymy, which means that we lose a systematic generalization.

\section{Gradience in language}

Linguistic gradience is relevant with respect to both the general relationship between lexicon and grammar and the more specific relationship between metonymy and word-formation. The gradience of linguistic phenomena is often more pervasive than we expect. Anyone who has worked with corpus and/or experimental data has discovered that some distinctions traditionally described in simple absolute terms turn out to be complex and scalar.

Brdar and Brdar-Szabó state that "Janda begins by drawing a parallel between lexical metonymy and word-formation metonymy”, using examples like The milk tipped over to illustrate lexical metonymy and examples like Czech květináč 'flower-pot' to illustrate word-formation metonymy. This statement is followed by the claim that "it is odd that lexical metonymy should be distinguished from word-formation metonymy, or grammatical metonymy" and further that such a distinction between lexicon and grammar "goes against the very grain of cognitive linguistics".

I would argue that drawing a parallel does not constitute drawing a boundary. A parallel can be drawn across parts of a continuum. Cognitive linguistics is rife with parallels drawn across the lexical vs. grammatical ends of the linguistic continuum. For example, prototypicality effects, radial category structures, and symbolic assemblies are posited both for items close to the lexical end of the continuum and for items toward the grammatical end (Langacker 2013: 18-23; Lakoff 1987: 289-292). Furthermore, the lack of a clear boundary between lexicon and 
grammar does not prevent us from recognizing any difference at all. A linguist is justified in sorting most words into the lexicon and most grammatical function markers (such as case, number, and tense inflections) into the grammar, provided of course that $\mathrm{s} /$ he is sensitive to transitional phenomena. Cf. Langacker's statement on this matter:

Overlap among lexicon, morphology, and syntax does not prevent us from defining them and drawing useful distinctions, any more than the absence of a precise boundary between green and blue condemns us to seeing only grue - a gradation does not imply undifferentiated homogeneity. Langacker (2013: 6-7)

The milk tipped over is a prototypical and oft-cited example of lexical metonymy. Czech květináč 'flower-pot' represents a parallel shift in which a container is accessed by reference to its contents, but here the shift is achieved by overt grammatical means. The fact that lexicon and grammar belong to a single continuum does not blind a linguist from seeing that milk undergoes the shift as a monomorphemic lexeme, whereas with květináč 'flower-pot' the shift is achieved via derivation.

Brdar and Brdar-Szabó do not offer an explicit definition of metonymy, however they clearly hold to a definition that eschews morphological marking within a word. This definition is narrower than the one given in Janda (2011), cited here in Section 3. Given a narrow definition of metonymy like that preferred by Brdar and Brdar-Szabó, it is necessary to exclude metonymy from word-formation. One then has to decide exactly where to draw the line. There are instances of gradation in the relationship between lexical metonymy and grammatical (wordformational) metonymy that provide challenges. Lipka (1992: 121) gives these examples:

(1) a. host n. $\rightarrow$ host $\emptyset \mathrm{v}$. 'be, act as a host'

b. patron n. $\rightarrow$ patron/ize v. 'be, act as a patron'

Most linguists agree that conversion as in (1a) is metonymic. Brdar and BrdarSzabó recognize metonymy only in relation to whole words, not suffixes ("it is not suffixes that exhibit metonymy, ... but whole words"), so the relationship between Lipka's examples cannot be drawn under their definition of metonymy. Regardless of one's preferred definition of metonymy, one would want to recognize the parallel between (1a) and (1b).

If we return to milk, we can see a cline from clearly lexical to clearly word-formational expressions, all involving metonymic (or "metonymic-like") patterns: 
Table 1: A cline of metonymic patterns

\begin{tabular}{|c|c|c|c|c|}
\hline no derivation & milk $\mathrm{n}$. & lexeme & $\begin{array}{l}\text { CONTAINED FOR } \\
\text { CONTAINER }\end{array}$ & $\begin{array}{l}\text { as in The milk tipped } \\
\text { over }\end{array}$ \\
\hline $\begin{array}{l}\text { zero derivation } \\
\text { (conversion) }\end{array}$ & milk v. & conversion & $\begin{array}{l}\text { PRODUCT FOR } \\
\text { ACTION }\end{array}$ & $\begin{array}{l}\text { as in The farmer will } \\
\text { milk his cows }\end{array}$ \\
\hline overt derivation & milker $\mathrm{n}$. & $\begin{array}{l}\text { morphological } \\
\text { derivation }\end{array}$ & $\begin{array}{c}\text { ACTION FOR } \\
\text { AGENT }\end{array}$ & $\begin{array}{l}\text { as in She is a good } \\
\text { milker }\end{array}$ \\
\hline
\end{tabular}

It is not clear that there is any non-arbitrary way to choose where or even whether to impose boundaries along this continuum. One could assert that there is a clear difference between the noun milk, which is non-derived, and the two derived words milk as a verb and milker, but this would overlook the fact that milk has the same form as both a noun and a verb and for both metonymy is observed at the level of the whole word. Alternatively, one could attempt to draw a line between milk as both noun and verb on the one hand, and milker on the other hand, based on purely formal characteristics since milk has no overt derivational morphology, whereas milker is overtly derived. However, it would be strange to invoke different cognitive strategies for the two types of derivation. Additionally, there is the fact that conversion in the verb milk is zero derivation only in part of the paradigm; in the forms milks, milked, and milking we observe overt verbal morphology. So do we invoke metonymy only for the infinitive and most of the present tense (excluding the third person singular), but some other strategy for the remaining verb forms?

This problem is compounded when we look at languages with different systems of morphological derivation. Some languages (like English) have rather meager morphological systems and rely more heavily on lexical metonymy and conversion, whereas other languages use affixation to achieve the same expressive goals. Patterns of morphological derivation are to a large extent language specific, reflecting the historical development of a language. If we return to Lipka's example in (1a) above and translate it into Russian, we get a different result: the noun is xozjain 'host', but the verb xozjajničat' 'act as a host' is overtly derived from xozjain, with the suffix -ničat'. So is the relationship between 'host' and 'be a host', reflected in words that are transparently related in form in both languages, metonymic in English but non-metonymic in Russian? Do we want to assert a different cognitive strategy for Russian than for English? Is it the case that some languages are inherently more metonymic (assuming a narrow definition of metonymy)? Or is it the case that languages are similar in their conceptual use of metonymy, but differ in how it is expressed (i.e., by whole words vs. affixes)? I 
would argue for the latter, not the former, and point out that a narrow definition does not facilitate typological comparison across languages.

By insisting that my "claim about metonymy being involved in wordformation phenomena such as suffixation is misconceived" and that metonymy is restricted to "whole words", Brdar and Brdar-Szabó in effect have posited that the cognitive mechanism of metonymy functions only on the level of whole words and their constructions. One could argue that it is they, not I, who thus run afoul of the central tenet of cognitive linguistics that lexicon and grammar form a continuum, since they thus posit a boundary between whole (lexical) words and word-internal morphology.

\section{Domain and context}

Kövecses and Radden (1998: 39) define metonymy as "a cognitive process in which one conceptual entity, the vehicle, provides mental access to another conceptual entity, the target, within the same domain, or ICM", using the terms "ICM" and "domain" interchangeably. Brdar and Brdar-Szabó state that "Janda replaces the notion of ICM with that of 'context" ". While "domain" and "ICM" do not explicitly appear in my definition, I do not deny or ignore the role of the domain in metonymy in Janda (2011). My article contains a summary of various strategies scholars have used in defining metonymy and domains/dominions have their rightful place in that discussion (citing Croft 1993; Langacker 1993, 2009; Ruiz de Mendoza 2000), alongside contiguity (citing Jakobson 1980 [1956]; Peirsman and Geeraerts 2006), and Frames/ICMs (citing Kövecses and Radden 1998; Radden and Kövecses 1999; Panther and Thornburg 1999; Barcelona 2002). However, I do not arbitrate among these strategies. I focus instead on the common ground they share because the differences between them do not significantly impact the goal of my study, which is merely to explore parallels between lexical metonymy and word-formation. I follow the contiguity strategy more closely because some of its proponents offer a detailed classification of lexical metonymy (Peirsman and Geeraerts 2006) that proves useful in my study. However, I do recognize the domain as a useful concept, and my approach is compatible with those that employ the concept of domain.

The definition I use in my article focuses on "the semantic relationships between the source word, the derived word, and the affix as the context for metonymy" (Janda 2011: 388). In word-formation, the affix serves as an "overt cue to the presence of metonymy”.

Brdar and Brdar-Szabó argue that "context is a notoriously slippery term in linguistics" and therefore not useful in describing metonymy. One could counter 
that slippery concepts are abundant in linguistics and indeed that the concept of domain is no less slippery. Piersman and Geeraerts (2006: 269-270) argue that the notion of domain is too vague a foundation for an operational definition of metonymy. The concept of domain is inherently problematic in that our world does not come with crisply delimited domains, making it difficult if not impossible to determine whether domains overlap and whether a mapping is across domains or within a single domain. The context a linguistic expression appears in is on the contrary relatively more concrete, something that is easier to observe and agree on.

Alternatively, one could ask how it could be possible for metonymy to exist without context. Is milk capable of expressing a container in the absence of a context like tipped over? There are examples in which a historical change has replaced an original source meaning with a metonymic target as in French la saison 'season' (which originally meant 'act of sowing'), but such examples are arguably in a different league than prototypical lexical metonymies, which require a context. The point in Janda (2011) is that there is a parallel between the context that signals a lexical metonymy and the affix that signals a word-formation metonymy.

\section{Data and diagram}

Brdar and Brdar-Szabó make a number of extrapolations beyond the claims and data presented in Janda (2011), in relation to compounding, prefixation, morphological inflection, and the structure and history of English. They then criticize the results that might ensue from these extrapolations. They also offer a diagram to represent my model of metonymy. I do not recognize my work in these extrapolations or in this diagram and therefore refrain from commenting on them.

All of the data that Janda (2011) was based on has been and continues to be publicly available on my website. ${ }^{1}$ Anyone is welcome to inspect, verify, and react to that data.

\section{Conclusion}

Differences of opinion are a healthy part of academic inquiry. Is there any need to draw lines between colleagues, conferring on some the label "metonymy people"

1 http://ansatte.uit.no/laura.janda/mypubs/mypubs.html 
while excluding others from this group, or to classify an alternative approach as "a completely wrong direction" as asserted by Brdar and Brdar-Szabó?

The community of cognitive linguists would be well served by further investigations into the relationship between metonymy and word-formation. Ideally such a debate should give researchers a chance to work together toward a better understanding of the relevant phenomena while recognizing and respecting differences of opinion. Opinions, however, should be informed by data, and to that end we need to collect more data. It would be useful to have datasets parallel to those in Janda (2011) but representing other languages, particularly non-IndoEuropean languages. With more and better information we can all move forward on these issues.

Acknowledgments: I thank Dirk Geeraerts, Ronald W. Langacker, Tore Nesset, Günter Radden, and two anonymous reviewers for valuable input.

\section{References}

Barcelona, Antonio. 2002. Clarifying and applying the notions of metaphor and metonymy within Cognitive Linguistics: An update. In René Dirven \& Ralf Pörings (eds.), Metaphor and metonymy in comparison and contrast (Cognitive Linguistics Research 20), 207-278. Berlin: Mouton de Gruyter.

Brdar, Mario \& Rita Brdar-Szabó. (this volume) Where does metonymy begin? Some comments on Janda (2011).

Croft, William. 1993. The role of domains in the interpretation of metaphors and metonymies. Cognitive Linguistics 4(4), 335-370.

Jakobson, Roman. 1980 [1956]. Two aspects of language and two types of aphasic disturbances. In Roman Jakobson \& Morris Halle (eds.), Fundamentals of language, 67-96. The Hague: Mouton.

Janda, Laura A. 2008. Metonymy via perfectivization of Russian verbs. Slavica Helsingiensia 35 (S ljubov'ju k slovu [With love for the word]. Festschrift in honour of Professor Arto Mustajoki on the occasion of his 60th birthday). 77-85.

Janda, Laura A. 2011. Metonymy in word-formation. Cognitive Linguistics 22(2), 359-392.

Kövecses, Zoltán \& Günter Radden. 1998. Metonymy: Developing a cognitive linguistic view. Cognitive Linguistics 9(1), 37-77.

Lakoff, George. 1987. Women, fire and dangerous things. Chicago: University of Chicago Press. Langacker, Ronald W. 1993. Reference-point constructions. Cognitive Linguistics 4(1), 1-38. Langacker, Ronald W. 2009. Metonymic grammar. In Klaus-Uwe Panther, Linda L. Thornburg \& Antonio Barcelona (eds.), Metonymy and metaphor in grammar, 45-71. Amsterdam: John Benjamins.

Langacker, Ronald W. 2013. Essentials of Cognitive Grammar. Oxford: Oxford University Press. Lipka, Leonhard. 1992. An outline of English lexicology, $2^{\text {nd }}$ edn. Tübingen: Max Niemeyer Verlag. 
Panther, Klaus-Uwe \& Linda Thornburg. 1999. The potentiality for actuality metonymy in English and Hungarian. In Klaus-Uwe Panther \& Günter Radden (eds.), Metonymy in language and thought, 337-357. Amsterdam: John Benjamins.

Peirsman, Yves \& Dirk Geeraerts. 2006. Metonymy as a prototypical category. Cognitive Linguistics 17(3), 269-316.

Radden, Günter \& Zoltán Kövecses. 1999. Towards a theory of metonymy. In Klaus-Uwe Panther \& Günter Radden (eds.), Metonymy in language and thought, 17-59. Amsterdam: John Benjamins.

Ruiz de Mendoza, Francisco J. 2000. The role of mappings and domains in understanding metonymy. In Antonio Barcelona (ed.), Metaphor and metonymy at the crossroads: A cognitive perspective, 109-132. Berlin: Mouton de Gruyter. 